\title{
Effects of immediate unilateral whole body vibration on muscle performance and balance in young adults
}

\author{
Junhyuck Park ${ }^{\mathrm{a}}$, Wonjae Choi ${ }^{\mathrm{a}}$, Seungwon Lee ${ }^{\mathrm{b}}$ \\ ${ }^{a}$ Institute of Cardiocerebrovascular Disease Rehabilitation Research, Seoul, Republic of Korea \\ ${ }^{b}$ Department of Physical Therapy, College of Health and Welfare, Sahmyook University, Seoul, Republic of Korea
}

Objective: Whole body vibration training is a relatively new approach for enhancement of muscle strength, physical performance, and balance. The aim of this study was to assess the effect of unilateral whole body vibration training.

Design: One group pretest-posttest design.

Methods: Sixteen healthy, physically active volunteers participated in this study. Whole body vibration was applied with a frequency of $20 \mathrm{~Hz}$ and an amplitude of $3 \mathrm{~mm}$ for 3 minutes. Muscle performance and static balance were assessed before and after unilateral whole body vibration training. One leg standing broad jump test was measured to determine muscle performance which is closely linked to lower extremity muscle function. The good balance system was used in evaluation static balance. All test were measured 3 times and the average value was analyzed.

Results: Jumping length was significantly improved by $0.11 \mathrm{~m}$ in all participants after intervention $(p<0.05)$. Among static parameters, significant results were observed where in the eyes opened condition, X-speed (medial-lateral sway) changed from 4.20 $\mathrm{mm} / \mathrm{s}$ to $4.95 \mathrm{~mm} / \mathrm{s}$, Y-speed (anterior-posterior sway) changed from $5.77 \mathrm{~mm} / \mathrm{s}$ to $6.54 \mathrm{~mm} / \mathrm{s}$ and velocity moment changed from $12.77 \mathrm{~mm}^{2} / \mathrm{s}$ to $13.57 \mathrm{~mm}^{2} / \mathrm{s}(p<0.05)$. In the eyes closed condition, X-speed changed from $4.34 \mathrm{~mm} / \mathrm{s}$ to $4.85 \mathrm{~mm} / \mathrm{s}$, Y-speed changed from $7.84 \mathrm{~mm} / \mathrm{s}$ to $8.16 \mathrm{~mm} / \mathrm{s}$ and velocity moment changed from $16.03 \mathrm{~mm}^{2} / \mathrm{s}$ to $16.11 \mathrm{~mm}^{2} / \mathrm{s}(p<0.05)$.

Conclusions: Immediate unilateral whole body vibration improved muscle performance but impaired static balance in young adults.

Key Words: Balance, Muscle performance, Unilateral, Whole body vibration

\section{Introduction}

The ability to control balance of the body is an important prerequisite to performance of functional activities [1] and its failure can seriously limit performance and quality of life [2]. The most current measures for assessment of the postural sway are related to the excursion of the center of pressure [3], which has been widely used in studies reported in the literature [4]. Several postural parameters in the time and/or frequency domains have been reported according to the center of pressure excursion [5]. Postural parameters in the time domain have been used extensively in quantification of pos- tural stability [6].

Whole body vibration is a type of exercise that uses high-frequency mechanical irritation, which are generated by a vibrating platform and transmitted through the body. This technology may be attractive particularly for subjects who are otherwise unable or unwilling to perform conventional exercise and will therefore be a promising option for increasing subjects' physical activity of subject [7]. Whole body vibration training can have advantageous effects on the proprioceptive mechanisms of the ankle joint because with this intervention, it is possible to impact the muscle performance, electromyography responses, as well as muscular

Received: 5 October, 2013 Revised: 14 December, 2013 Accepted: 16 December, 2013

Corresponding author: Seungwon Lee

Department of Physical Therapy, College of Health and Welfare, Sahmyook University, 815 Hwarang-ro, Nowon-gu, Seoul 139-742, Republic of Korea Tel: 82-2-3399-1630 Fax: 82-2-3399-1639 E-mail: swlee@syu.ac.kr

(c) This is an Open-Access article distributed under the terms of the Creative Commons Attribution Non-Commercial License (http://creativecommons.org/licens es/by-nc/3.0) which permits unrestricted non-commercial use, distribution, and reproduction in any medium, provided the original work is properly cited.

Copyright @ 2013 Korean Academy of Physical Therapy Rehabilitation Science 
strength [8]. This type of training was applied in sport performance through the research of Ramas et al. [9]. In recent years, whole body vibration training has been utilized more as a neuromuscular training technique [10] and as a method for injury rehabilitation and prevention method [11]. Some authors have suggested that whole body vibration training can be used for improvement of balance and proprioception [12]. There is some evidence indicating that whole-body vibration training can improve neuromuscular function [13].

Therefore, this study investigated the immediate effect of unilateral whole body vibration training on muscle performance and static balance. We hypothesized that unilateral whole body vibration would result in significant improvement of muscle performance and static balance.

\section{Methods}

\section{Subjects}

The study was designed as a pilot trial for young adults who had been in attending at Sahmyook University. Sixteen healthy, physically active volunteers participated in this study. The inclusion criteria were age between 20 and 35 years. Exclusion criteria included any type of injury within six months prior to conduct of the study.

Muscle performance was evaluated using the one leg standing broad jump test. We modified the existing research procedure by having the subject jump vertically [14]. At that

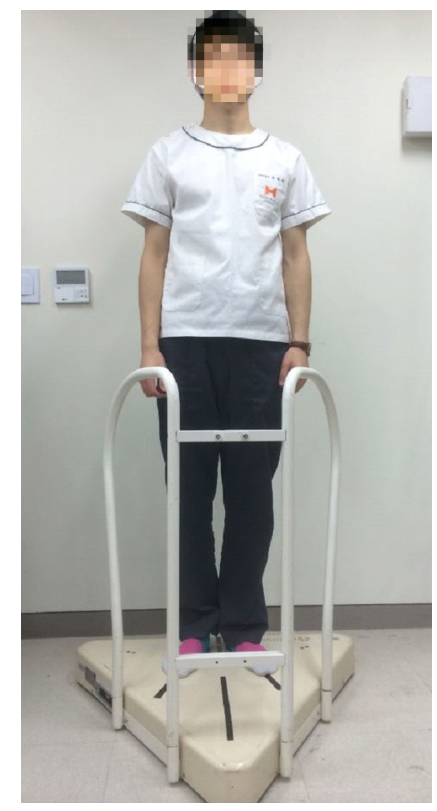

Figure 1. Standing on one leg to the dominant side. time, all subjects jumped on the dominant leg as much as possible and then the jumping length was measured.

Static balance was measured using the good balance system (Good Balance System; Metitur Ltd., Jyväskylä, Finland, 2008). The Good Balance system consists of an equilateral triangular force platform connected to a computer. The following measurements were carried out with the subject standing on the force platform: (1) normal standing for $30 \mathrm{~s}$ with eyes opened, hands hanging down loosely, feet comfortably apart, and gaze fixed on forward at eye level; (2) normal standing as above for $30 \mathrm{~s}$ but with eyes closed. The tests were performed three times in the same order for every subject (Figure 1).

\section{Intervention}

This study used whole body vibration (Galilieo advanced plus; Novotec, Pforzheim, Germany, 2011). Frequency and amplitude parameters were $20 \mathrm{~Hz}$ and $3 \mathrm{~mm}$ for 3 minutes. Type of vibration of this machine was vertical. Participants were instructed as follows. First, the subject remained with one leg to the dominant side. Second, the subject bent his or her knee approximately $120^{\circ}$ (Figure 2 ). Third, the subject remained in a squatting position, maintaining weight bearing on the toes [15].

\section{Data analysis}

SPSS version 15.0 for Windows (SPSS Inc., Chicago, IL,

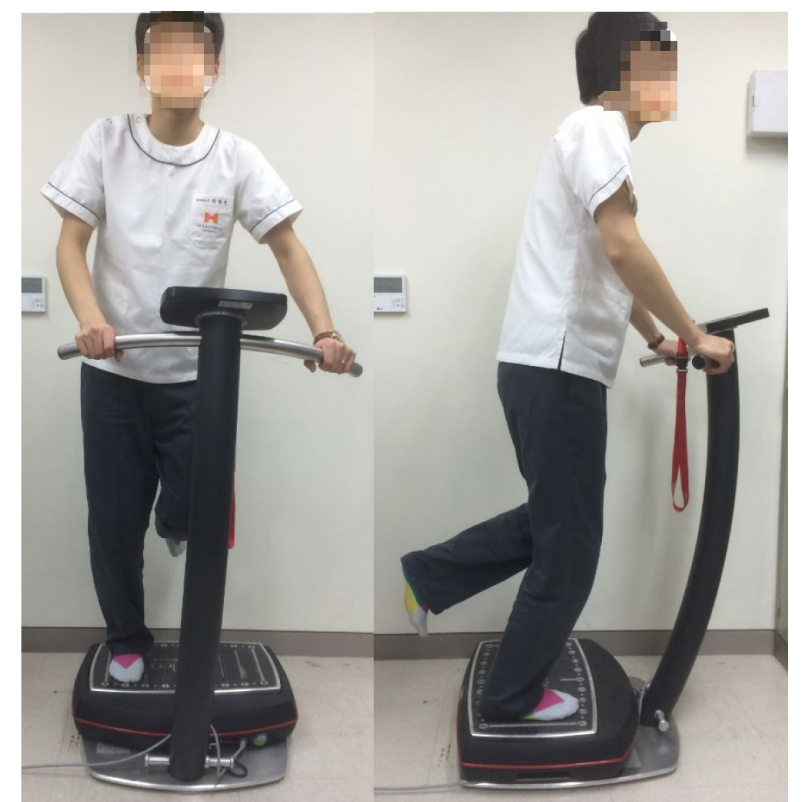

Figure 2. Standing on one leg with knee flexed approximately 120 degrees. 
Table 1. General characteristics of the subjects

$(\mathrm{N}=16)$

\begin{tabular}{lc}
\hline \multicolumn{1}{c}{ Characteristic } & Value \\
\hline Age $(\mathrm{yr})$ & $28.40(6.34)$ \\
Height $(\mathrm{cm})$ & $166.92(8.13)$ \\
Weight $(\mathrm{kg})$ & $61.29(14.86)$ \\
Dominant foot (right/left) & $13 / 3$ \\
\hline
\end{tabular}

Values are presented as $\mathrm{n}$ or mean (SD).

USA) was applied for statistical analysis of the results. Descriptive statistics was used for general history of subjects. Paired t-test was performed for comparison of jumping performance and static balance. The alpha level was set at 0.05 for all analyses.

\section{Results}

This study was conducted on 16 subjects, whose general characteristics are listed in Table 1. Muscle performance, which was evaluated based on jumping length, showed a significant change, from $0.93 \mathrm{~m}$ to $1.04 \mathrm{~m}(p<0.05)$, and static balance was evaluated based on postural sway. In the eyes opened condition, X-speed (mediolateral sway) changed from $4.20 \mathrm{~mm} / \mathrm{s}$ to $4.95 \mathrm{~mm} / \mathrm{s}(p<0.05)$, Y-speed (anterioposterior sway) changed from $5.77 \mathrm{~mm} / \mathrm{s}$ to 6.54 $\mathrm{mm} / \mathrm{s}$ and velocity moment changed from $12.77 \mathrm{~mm}^{2} / \mathrm{s}$ to $13.57 \mathrm{~mm}^{2} / \mathrm{s}(p<0.05)$. In the eyes closed condition, $\mathrm{X}$-speed changed from $4.34 \mathrm{~mm} / \mathrm{s}$ to $4.85 \mathrm{~mm} / \mathrm{s}(p<0.05)$, Y-speed changed from $7.84 \mathrm{~mm} / \mathrm{s}$ to $8.16 \mathrm{~mm} / \mathrm{s}$ and velocity moment changed from $16.03 \mathrm{~mm}^{2} / \mathrm{s}$ to $16.11 \mathrm{~mm}^{2} / \mathrm{s}(p$ $<0.05$; Table 2).

\section{Discussion}

The current study was conducted in order to identify the effects of immediate unilateral whole body vibration on muscle performance and balance of young adults. The findings of this study showed that vibration induced an increase in muscle performance and a decrease in static balance.

Some of the long-term effects of this type of training involved increases in muscular strength [16], power [17] and jump length [14]. There are different theories that may explain the reason for these improvements. Some authors have stated that they may be due to muscle adaptations produced by the gravitational load. Acute physiological adaptations to whole body vibration training are related to an increase in the sensitivity of muscle spindles, of gamma motor neurons,
Table 2. Comparison of the static balance with eye opened, eye closed and jumping length

\begin{tabular}{lccc}
\hline \multicolumn{1}{c}{ Parameter } & Pre-test & Post-test & $p$ \\
\hline Jumping $(\mathrm{m})$ & $0.93(0.30)$ & $1.04(0.28)$ & 0.045 \\
EO & & & \\
$\quad$ X-speed (mm/s) & $4.20(2.17)$ & $4.95(2.12)$ & 0.000 \\
$\quad$ Y-speed (mm/s) & $5.77(1.90)$ & $6.54(1.87)$ & 0.006 \\
$\quad$ Velocity moment & $12.77(9.91)$ & $13.57(9.13)$ & 0.398 \\
$\quad\left(\mathrm{~mm}^{2} / \mathrm{s}\right)$ & & & \\
EC & & & \\
$\quad$ X-speed (mm/s) & $4.34(2.87)$ & $4.85(2.82)$ & 0.045 \\
Y-speed (mm/s) & $7.84(4.95)$ & $8.16(4.29)$ & 0.483 \\
$\quad$ Velocity moment & $16.03(27.84)$ & $16.11(22.02)$ & 0.970 \\
$\quad\left(\mathrm{~mm}^{2} / \mathrm{s}\right)$ & & & \\
\hline
\end{tabular}

Values presented as mean (SD).

EO: eyes opened, EC: eyes closed.

and their effects on the stretch-shortening reflex [18].

Therefore, according to the results of our study, jumping length increased by approximately $11.8 \%$. This finding reflected results similar to those of previous studies [14]. However, static balance showed a significant decrease in the eyes opened condition. In general previous studies had applied whole body vibration for long term and both feet [15]. However, this study applied whole body vibration one time, and static balance was then measured immediately. Results showed that whole body vibration induced an increase in bone density. This is because, with continuing vibration, a larger proportion of the incident vibration energy is directed to bones, instead of being absorbed by muscle tissue [19].

It is suggested that stress on the lower extremity muscle produced fatigue, which may have produced a negative effect on static balance.

There were two limitations to this study. First, due to a small sample size, it is difficult to make any generalization. Second, since this study was a one-group pretest-posttest study, further studies are needed to investigate for the long term intervention effects to unilateral whole body vibration.

The findings described above suggest that vibration is a potentially efficient training stimulus and future studies should focus on evaluation of the long-term effects of whole body vibration on body muscle performance and balance.

\section{References}

1. Figura F, Cama G, Capranica L, Guidetti L, Pulejo C. Assessment of static balance in children. J Sports Med Phys Fitness 1991;31:235-42.

2. Baker CP, Newstead AH, Mossberg KA, Nicodemus CL. 
Reliability of static standing balance in nondisabled children: comparison of two methods of measurement. Pediatr Rehabil 1998;2:15-20.

3. Hof AL, Gazendam MG, Sinke WE. The condition for dynamic stability. J Biomech 2005;38:1-8.

4. Wrisley DM, Whitney SL. The effect of foot position on the modified clinical test of sensory interaction and balance. Arch Phys Med Rehabil 2004;85:335-8.

5. Cherng RJ, Lee HY, Su FC. Frequency spectral characteristics of standing balance in children and young adults. Med Eng Phys 2003;25:509-15.

6. McGraw B, McClenaghan BA, Williams HG, Dickerson J, Ward DS. Gait and postural stability in obese and nonobese prepubertal boys. Arch Phys Med Rehabil 2000;81:484-9.

7. Fujimoto C, Murofushi T, Sugasawa K, Chihara Y, Ushio M, Yamasoba T, et al. Assessment of postural stability using foam posturography at the chronic stage after acute unilateral peripheral vestibular dysfunction. Otol Neurotol 2012;33:432-6.

8. Kemmler W, von Stengel S. Alternative exercise technologies to fight against sarcopenia at old age: a series of studies and review. J Aging Res 2012;2012:109013.

9. Ramas J, Courbon A, Roche F, Bethoux F, Calmels P. Effect of training programs and exercise in adult stroke patients: literature review. Ann Readapt Med Phys 2007;50:438-44, 430-7.

10. Ritzmann R, Kramer A, Gruber M, Gollhofer A, Taube W. EMG activity during whole body vibration: motion artifacts or stretch reflexes? Eur J Appl Physiol 2010;110:143-51.

11. Moezy A, Olyaei G, Hadian M, Razi M, Faghihzadeh S. A comparative study of whole body vibration training and conventional training on knee proprioception and postural stability after anterior cruciate ligament reconstruction. Br J Sports Med 2008;42:
373-8.

12. Hopkins T, Pak JO, Robertshaw AE, Feland JB, Hunter I, Gage $\mathrm{M}$. Whole body vibration and dynamic restraint. Int J Sports Med 2008;29:424-8.

13. Rittweger J. Vibration as an exercise modality: how it may work, and what its potential might be. Eur J Appl Physiol 2010;108: 877-904.

14. Torvinen S, Kannus P, Sievänen H, Järvinen TA, Pasanen M, Kontulainen S, et al. Effect of four-month vertical whole body vibration on performance and balance. Med Sci Sports Exerc 2002;34:1523-8.

15. Martínez F, Rubio JA, Ramos DJ, Esteban P, Mendizábal S, Jiménez F. Effects of 6-week whole body vibration training on the reflex response of the ankle muscles: a randomized controlled trial. Int J Sports Phys Ther 2013;8:15-24.

16. Delecluse C, Roelants M, Verschueren S. Strength increase after whole-body vibration compared with resistance training. Med Sci Sports Exerc 2003;35:1033-41.

17. Russo CR, Lauretani F, Bandinelli S, Bartali B, Cavazzini C, Guralnik JM, et al. High-frequency vibration training increases muscle power in postmenopausal women. Arch Phys Med Rehabil 2003;84:1854-7.

18. Verschueren SM, Roelants M, Delecluse C, Swinnen S, Vanderschueren D, Boonen S. Effect of 6-month whole body vibration training on hip density, muscle strength, and postural control in postmenopausal women: a randomized controlled pilot study. J Bone Miner Res 2004;19:352-9.

19. Torvinen S, Kannu P, Sievänen H, Järvinen TA, Pasanen M, Kontulainen S, et al. Effect of a vibration exposure on muscular performance and body balance. Randomized cross-over study. Clin Physiol Funct Imaging 2002;22:145-52. 